\title{
Young Adult Sleep Health during COVID-19 Pandemic
}

\author{
Kathy Sexton-Radek \\ Elmhurst University, Elmhurst, IL, USA \\ Email:ksrsleep@aol.com
}

How to cite this paper: Sexton-Radek, K. (2021) Young Adult Sleep Health during COVID-19 Pandemic. Health, 13, 369-377. https://doi.org/10.4236/health.2021.134030

Received: March 14, 2021

Accepted: April 17, 2021

Published: April 20, 2021

Copyright $\odot 2021$ by author(s) and Scientific Research Publishing Inc. This work is licensed under the Creative Commons Attribution International License (CC BY 4.0).

http://creativecommons.org/licenses/by/4.0/

\begin{abstract}
Young adults, as a group, have poor quality sleep. While possessing the knowledge of the value of sleep health, young adults often allow their social schedules to encroach upon sleep time. Since March of 2020, the prevalence of COVID-19 reached a rate where quarantine, shelter in place mandates were employed worldwide. The obvious public health necessity of this action, along with the uncertainty with increasing rates of COVID-19 is compounded by distribution issues related to the vaccine. This literature review presents the factors related to young adult sleep followed by psychological consequences of COVID-19 factors. Several studies identify the need to attend to not only the sleep quality needs of young adult sleep but also the increased number of reporting depressed mood. Suggestions for improvement of young adult sleep given the factors of quarantine and uncertainty due to the COVID-19 pandemic are provided.
\end{abstract}

\section{Keywords}

Sleep Health, COVID-19, Quarantine, Depression

\section{Introduction}

Colleges and universities are ranked third behind bars and restaurants as a source of COVID-19 contagion in online postings. Colleges and universities are the academic home for the student coming into themselves as a scholar, an adult in the world and as their own person. So, as it seems, the change in this setting, most predominantly to remote, also shifts the resources provided to the young adult. Consequently young adults have had to change their behavior patterns which may impact their sleep health.

Sleep health is a public health concern. Inadequate sleep is associated with poor grades, deficient cognitive functioning, and predisposition to depression, 
heart disease, and diabetes [1]. In a measurement of sleep length, cell phone use and sedentary time using the sedentary app [2], reported an increase in anxiety, depression related to news coverage of COVID-10 in the U.S. media [1] [3] [4]. It is possible that the increased social media use during the quarantine worsens the factors related to mental health.

\section{Impact of the Quarantine}

The implementation of quarantine policies in the United States for the development of herd immunity and regulation of COVID-19 outbreak began in Spring, 2020. Sleep disturbances impact on health and quality of life is a public health challenge [5]. An increase in anti-depression medication prescriptions at the onset of outbreak in the United States implies poor sleep linked to depression association [5].

Results from a sleep app called "Sleep Cycle" of respondents, worldwide, indicated increased sleep and longer (approximately 37\%) sleep onset latency times (https://www.sleepcycle.com/coronavirus/). Additionally, the changes in routine secondary to the "shelter in place" mandate lead to increasing levels of anxiety and depression secondary to loneliness, isolation and unemployment factors. Further, documented cases of individuals with diagnosed mental health conditions of depression and anxiety experienced increases in symptoms with a rise in suicide rates [6] [7] [8] [9].

Young adults (13 - 30 years) are a vulnerable population given their developmental level of skills to manage psychological/emotional/social challenges. By contrast, the only population that slept worse than young adults, survey findings indicated, were health care providers. A gender difference prevailed with women, according to the sleep cycle survey reporting sleep difficulties twice as much as men, across all ages [10]. Thus, the greatest impact on sleep to young adults reflects the magnitude of change in their daily routine. The sleep cycle survey reported 50\% of young adult respondents experienced difficulty falling asleep (sleep onset latency) [10]. The transition to remote learning, connecting less and spending less time in daylight were reported by young adult sleep cycle respondents. Collectively this group reported feeling more anxious (47.6\%) and more depressed (34.8\%) than before the start of the COVID-19 pandemic and shelter in place mandate (https://www.sleepcycle.com/coronavirus/). The loss of daytime light is experienced by young adults in two ways: 1) increased technology use, leisure (e.g., Netflix, Hulu, gaming) and 2) remote learning classes. The net effect of increased technology use is increased amount of blue light from devices and a reduction in natural sunlight. Both outcomes result in a disruption in circadian sleep cycle due to the inhibition of melatonin release and control of sleep wake cycle. Young adults are worried about being lonely, becoming ill as well as experiencing diffuse upset (http://www.sleepcycle.com/coronavirus/).

A tracer to measure a metabolic waste product inside neuron brain cells [11]. A buildup of this metabolic product has been associated with Alzheimer's disease 
and impaired brain function. In a comparison of scans from young adult participants groups of normal night of sleep and one of 31 hours sleep deprivation, [11] reported changes mid-brain structure functioning (hippocampus-memory, amygdala-emotion). The sleep deprived group performed poorer on vigilance and attention tasks as well as reported more metabolic waste product.

Evidence of dissociative functioning in young adults following high levels of daily stress has been identified [3]. The participants experienced fatigue, insomnia and content of dreams while enduring daily stress. Stress triggers brain activation of limbic system functioning and consequentially activation of endocrine functioning specifically adrenal cortex epinephrine and cortisol release [12] [13]. This excitatory function incites a hypervigilance in patients. Poor sleep quality in young adults, as measured by minutes to fall asleep, number and length of wake-ups and shortened sleep duration.

Positive results for EEG biofeedback with young adults in terms of increased cerebral blood flow that translates to efficient brain activity [8]. An analysis of sleep and activity in young adults that engaged regularly in activities that involved social engagement [6]. Less variability in wake time, it was found, leads to earlier exposure to bright light thus providing more opportunity for activity in the day and earlier bedtimes [6]. An association between obesity and self-reported sleep duration as measured by leptin levels and sleep logs [9]. Worsened sleep (i.e. sleep deprivation) is associated with reduced appetite inhibiting hormone leptin and an increase of appetite stimulating hormone ghrelin [6] [9].

Decreased cognitive performance and overall mood in young adults based on their measured difference of two hours weekday mornings and weekend mornings [10] [11]. Poor sleep hygiene in young adults has having both direct and indirect effects on their sleep quality [14].

\section{Impact of COVID-19: The Quarantine}

The COVID-19 pandemic, for safety and public health reasons, is to be managed by quarantine (e.g., frequent hand washing, six foot social distance). With this, the closing of schools, which from news sources as high-ranking sources of contagion of COVID-19, hence the transference to online courses [15] [16]. The online course setup removes, however, the college campus milieu, so instrumental in social development for young adults. For some young adults, it is essential to provide a sense of a safe environment with social supports to facilitate sleep [17] [18] [19] [20]. Young adults were queried and found to have reported more loneliness during the pandemic and had a greater use of social media [5].

\section{Approaching Solutions}

From a questionnaire study conducted with participants five months later with measured increases in resilience, grit, subjective happiness [15]. Perceived stress decreased significantly in the second measurement of participants [15]. The reconnection to relatives, increasing comfort in the home, reconnecting to rela- 
tionship [21] [22] [23] [24]. Additionally, a finding of a collective acceptance of the COVID-19 pandemic changes that were necessary (e.g. hand washing, 6' social distance, reduced social contact) [16]. Perceived stress concept using questionnaires to participants, again, in a pre to post manner [25] [26] [27]. This dispersal of questionnaires across several countries [27] [28]. Moderate levels of perceived stress was associated with fear and helplessness of being infected with COVID-19. Further, the sleep loss documented in sleep logs corresponded to the sustained, moderate levels pf perceived anxiety.

Young adults engage in high risk behaviors, struggles with health issues, and onset of conditions that are preventable by a healthier lifestyle [29] [30] [31] [32] [33]. In Table 1, reported sleep hygiene suggestions were tallied at one of the first post lockdown points in the United States. A survey study that young adults spend more time on gadget use than in class [34]. Now, with the quarantine condition, gadget use and computer use to social media has increased 30\% [25] [26].

\section{Coping}

Social support is a coping mechanism key to loneliness and isolation factors related to COVID-19 [26] [32] [33]. Increased mental health concerns of depression in young adults has been identified [33] [34]. The mediating effects of uncertainty that lead to depression are is identified as maladaptive coping and low adaptive coping [22] [34] [28]. It is imperative that adaptive coping. A series of suggestions to promote adaptive coping include the provision of education and information [25] [26]. Providing information about COVID-19 but an abundance, provide clear communications in terms of warning signs and ways/means to seek care, engage in meaningful activities [35] [36] [37].

In an effort to examine the factors that may lead to depression, investigations using questionnaires about depression have been used with results indicating sleep and Chronotype as interdependent with mood [20] [34]. In Table 2, several rigorous studies of sleep schedule (i.e., chronotypes such as eveningness or morningness where peak awareness is the evening or morning respectively). The implication of these findings point to the essential need to couple one's sleep

Table 1. Common suggestions to young adults to mediate quarantine insolation effects.

\begin{tabular}{cc} 
Exercise more & $29.0 \%$ \\
Have a consistent sleep schedule & $23.3 \%$ \\
Listen to white noise or sleeping music & $15.3 \%$ \\
Use drug, CBD oil or other supplements & $11.0 \%$ \\
Only use bedroom for sleeping or sex & $9.6 \%$ \\
Clean your bedroom more often & $9.5 \%$ \\
Use apps to help you sleep better & $8.7 \%$ \\
Nothing & $24.7 \%$ \\
\hline
\end{tabular}

Source: [15] [20] [30]. 
Table 2. Evidence table for the association between chronotype with depression and anxiety in post-secondary students.

\begin{tabular}{|c|c|c|c|}
\hline $\begin{array}{l}\text { Author, } \\
\text { year, } \\
\text { country }\end{array}$ & $\begin{array}{l}\text { Source population periods } \\
\text { of recruitment/data } \\
\text { collection }\end{array}$ & $\begin{array}{l}\text { Total number of } \\
\text { eligible subjects ( } n) \\
\text { Response rate (\%) }\end{array}$ & Outcomes of interest \\
\hline $\begin{array}{l}\text { Hirata, } \\
\text { et al. } \\
(2017) \\
\text { Brazil }\end{array}$ & $\begin{array}{l}\text { Medical students, } 19-30 \\
\text { y.o. (mean age }=22.1 \pm 2.1 \text { ), } \\
\text { in their first to fourth } \\
\text { semester of the medical } \\
\text { course at Federal University } \\
\text { of Ceará, Brazil, during a } \\
\text { 4-month period }\end{array}$ & $\begin{array}{l}n=161 \\
\text { Participation rate } \\
97 \% \\
\text { Females } 52.2 \% \\
\end{array}$ & $\begin{array}{l}\text { Depressive symptoms (BDI: score } \\
\text { range } 0 \text { - } 63,>10 \text { indicates } \\
\text { depressive symptoms). } \\
\text { Exposure measurement: } \\
\text { Home-Ostberg } \\
\text { morning/eveningnesss self-report } \\
\text { questionnaire (MEQ), score range } \\
16 \text { - } 86 \text { ) } \\
\text { classification of types into: } \\
\text { - Definitely evening }(26-30) \\
\text { - Moderately evening }(31-41) \\
\text { - Indifferent (42 - 58) } \\
\text { - Moderately morning }(59-69) \\
\text { - Definitely morning }(70-86)\end{array}$ \\
\hline
\end{tabular}

Key findings

The MEQ scores were inversely correlated to the BDI scores $(p=0.005)$

Odds of depressive symptoms in students with:

(a) Evening-type preference (definitely and moderately evening): $\mathrm{OR}=0.66(95 \% \mathrm{CI}$ $0.05,0.88$ )

(b) Evening-type preference after controlling for controlling for family history of depression: OR $=0.69(95 \%$ CI $0.52-0.93)$

(c) Evening-type preference after controlling for physical activity: OR $=0.66$ (95\% CI $0.49-0.89$ )

(d) Evening-type preference after controlling for family history of depression and physical activity: OR $=0.71(95 \% \mathrm{CI} 0.52$ 0.95)

Hsu et al. First-year undergraduate $\quad n=2919$

(2012) students (mean age $=19.4$ Participation rate y.o.) attending the National $79.2 \%$

Taiwan University, $\quad$ Females $=51.5 \%$ completed self-administered questionnaires at school in September 2002.

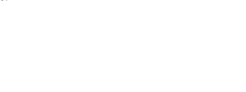

Prat et al. Undergraduate students $17 \quad n=517$

(2013) -30 y.o. $($ mean age $=21.4)$, Response rate $=$ Spain completed questionnaires $\quad 93.5 \%$ while attending a psychology course at the University of Barcelona
Females $66.5 \%$
Depression and anxiety symptoms Association between Chronotype and (BSRS domains): Items scored depression score in males $(F=6.32, p<0.01)$ : from 0 (not at all) to 4 (extremely), E vs I: Cohen's $d^{\sharp}=0.33$

with higher scores reflecting E vs M: Cohen's $d^{*}=0.55$ degrees of discomfort in past week. I vs M: Cohen's $d^{*}=0.22$ Exposure measurement $=\mathrm{M}-\mathrm{E} \quad$ Association between Chronotype and Scale (MES): score ranging from depression score in females $(F=13.89$, 13 to 55 , with higher scores $\quad p<0.001$ ): suggesting

morningness tendency:

Eveningness (E)

Intermediate (I)

E vs I: Cohen's $d^{*}=0.39$

E vs M: Cohen's $d^{*}=0.43$

I vs M: Cohen's $d^{\sharp}=0.04$

Association between Chronotype and anxiety
Morningness (M) score in males $(F=3.9 \mathrm{a} 2, p \leq 0.05)$

E vs I: Cohen's $d^{*}=0.31$

E vs M: Cohen's $d^{\sharp}=0.49$

I vs M: Cohen's $d^{\sharp}=0.18$

Psychological symptoms (GHQ-28): incorporates 4 subscales (psychosomatic symptoms, anxiety and insomnia, social dysfunction, and severe depression). Exposure measurement $=$ Spanish insomnia score: $F=7.74, p \leq 0.001$, partial version of the CSM: categories based on scores indicating evening-type $(\leq 25)$, neither-type (26 - 36), Morning-type ( $\geq 37)$.
Association between circadian typology (evening-,morning-, neither-type) and total GHQ-28 score: $F=11.02, p \leq 0.001$, partial

$n^{2}=0.041$

Association between circadian typology (evening-,morning-, neither-type) and $n^{2}=0.029$

Association between circadian typology (evening-,morning-, neither-type) and severe depression: $F=3.22, p \leq 0.05$, partial $n^{2}=0.029$

"Bonferroni method to adjust for multiple comparisons between chronotypes, $p \leq 0.05$. BDI Beck Depression Inventory, BSRS, Brief Symptom Rating Scale, $C I$ confidence interval, CSM composite scale of morningness, GHQ General Health Questionnaire 28, $M E Q$ morningness/evenings questionnaire, $M E S$ morningness-eveningness scale. $O R$ odds ratio, y.o. years old. *Adjusted for age, sex, smoking, alcohol drinking, stimulant use, body mass index, and physical activity. International Journal of Mental Health and Addiction (2019) 17:716-730. Source: [24]. 
schedule with a chronotype that is most suitable, otherwise the mismatch leads to maladaptive coping [29] [30] [31].

\section{Sleep Health}

Greater emphasis on sleep health for young adults as a public health focus is needed. Standard recommendations for sleep health are to be employed. Table 1 provides a summarization of young adult responses to how they have been spending their time. The sleep habits post lock down survey amplified the issue of poor sleep in young college students. These suggestions are strongly suggested for young adult sleep health: Regular wake up time, exposure to natural bright light, activity/exercise during the day approximately 4 hours before sleep, adequate hydration, two to three meals per day and advisedly some relaxation de-stressing routine (i.e., yoga, meditation). These sleep health recommendations are within the context of addressing the increasing mental health needs in young adults in terms of anxiety and depression [22]. While remote and fewer safe opportunities for mental health care, the necessary addressing loneliness in young adults can be accomplished. The use of telehealth for suicide prevention has been successful [15]. Mental health services addressing depression and suicide will also positively affect sleep health [21] [25] [31]. Specific recommendations for Young Adult Sleep would include adopting a stress management approach such as using a free app to guide them in a mindfulness relaxation [3] [30] [33]. Organizing one's time, a standard time management approach common to stress management would provide the Young Adult College student sleeper with control over their time and provide them with knowledge when they can study, work, sleep, eat and relax [3] [30] [33]. This level of specific schedules within schedules similar to the familiar "to do" list the student has for their assignments in a course can be used for the each segment of the day. For example, the morning can be divided into segments of wake-up hygiene, breakfast, study, break time with light snack, water and relaxation followed by a return to study [3] [30] [33] [38] [39]. These intervals of study could be replaced with remote classtime learning for the time being. The afternoon can be a further division of time to class time, study, relaxation and nutrition/hydration [3] [39]. The self-control of setting and keeping the schedule will provide some comfort and the net result of productivity and achievements from relaxation and nutrition/hydration will afford the Young Adult/College student with a balance of their time.

\section{Conflicts of Interest}

The author declares no conflicts of interest regarding the publication of this paper.

\section{References}

[1] Sexton-Radek, K. (2008) Sleep Quality in Young Adults. Edwin Mellon Publishers, New York. 
[2] Hutkins, J., Dasilva, A., Wang, W.C., Hedlund, E.L., Rogers, C., Nepal, S., et al. (2020) Mental Health and Behavior of College Students during the Early Phases of the COVID-19 Pandemic: A Longitudinal Smartphone and Ecological Momentary Assessment Study in College Students. https://doi.org/10.31234/osf.io/4enzm http://preprints.jmir.org/preprint/20185

[3] Sexton-Radek, K. (2011) An Examination of College Students' Health Knowledge. Journal of Health Education Research \& Development, 4, Article No. 188. https://doi.org/10.4172/2380-5439.1000188

[4] Gaultney, J. (2010) The Prevalence of Sleep Disorders in College Students: Impact on Academic Performance. Journal of American College Health, 59, 91-97. https://doi.org/10.1080/07448481.2010.483708

[5] Kutana, S. and Lau, P.H. (2020) The Impact of the 2019 Coronavirus Disease (COVID-19) Pandemic on Sleep Health. Canadian Psychology. (Advance Online Publication) https://doi.org/10.1037/cap0000256

[6] Carney, C.E., Edinger, J., Meyer, B., Lindman, L. and Istre, T. (2006) Daily Activities and Sleep Quality in College Students. Chronobiology International, 23, 623-637. https://doi.org/10.1080/07420520600650695

[7] Dudek, N. and Shahar, G. (2011) Daily Stress Interacts with Trait Dissociation to Predict Sleep-Related Experiences in Young Adults. Journal of Abnormal Psychology, 120, 719-729. https://doi.org/10.1037/a0022941

[8] Siever, D. (2012) Audio-Visual Entrainment: A Novel Way of Boosting Grades and Socialization While Reducing Stress in the Typical College Student. Biofeedback, 40, 115-124. https://doi.org/10.5298/1081-5937-40.3.02

[9] Pejovic, S. Vgontzas, A.N., Basta, M., Tsaoussoglou, M., Zoumakis, E., Vgontzas, A. Bixler, E.O. and Chrousos, E.P. (2010) Leptin and Hunger Levels in Young Healthy Adults after One Night of Sleep Loss. Journal of Sleep Research, 19, 552-558. https://doi.org/10.1111/j.1365-2869.2010.00844.x

[10] Peretti-Watel, P., Alleaume, C. Leger, D., Beck, F. and Verger, P. (2020) Anxiety, Depression and Sleep Problems: A Second Wave of COVID-19. General Psychiatry, 33, e100299. https://doi.org/10.1136/gpsych-2020-100299

[11] Wang, Q.Q., Kaelber, D.C., Xu, R. and Volkow, N. (2020) COVID-19 Risk and Outcomes in Patients with Substance Use Disorders: Analysis from Electronic Health Records in the United States. Molecular Psychiatry, 26, 20-39. https://doi.org/10.1038/s41380-020-00880-7

[12] Li, L., Wang, Y.Y., Wang, S.B., Zhang, L., Li, L., Xu, D.-D., et al. (2018) Prevalence of Sleep Disturbance in Chinese University Students: A Comprehensive Meta-Analysis. Journal of Sleep Research, 27, e12648. https://doi.org/10.1111/jsr.12648

[13] Yang, C. and Spielman, A. (2001) The Effect of a Delayed Weekend Sleep Pattern on Sleep and Morning Functioning. Psychology and Health, 16, 715-725. https://doi.org/10.1080/08870440108405869

[14] Peach, H., Gaultney, J.F. and Gray, D.D. (2018) Sleep Hygiene and Sleep Quality as Predictors of Positive and Negative Dimensions of Mental Health in College Students. Cogent Psychology, 3, Article ID: 1168768. https://doi.org/10.1080/23311908.2016.1168768

[15] Sturman, E.D. (2020) Coping with COVID-19: Resilience and Psychological Well-Being in the Midst of a Pandemic. Journal of Social and Clinical Psychology, 39, 561-570. https://doi.org/10.1521/jscp.2020.39.7.561

[16] Lifshin, U., Mikulincer, M. and Kretchner, M. (2020) Motivated Helplessness in the Context of the COVID-19 Pandemic: Evidence for a Curvilinear Relationship be- 
tween Perceived Ability to Avoid the Virus and Anxiety. Journal of Social and Clinical Psychology, 39, 479-497. https://doi.org/10.1521/jscp.2020.39.6.479

[17] Salerno, J.P., Williams, N.D. and Gattamorta, K.A. (2020) LGBTQ Population: Psychologically Vulnerable Communities in the COVID-19 Pandemic. Psychological Trauma: Theory, Research Practice and Policy, 12, S239-S242. https://doi.org/10.1037/tra0000837

[18] Alonzi, S., Torres, A. and Silverstein, M.W. (2020) The Psychological Impact of Preexisting Mental and Physical Health Conditions during the COVID-19 Pandemic. Psychological Trauma: Theory, Research, Practice and Policy, 12, S236-S238. https://doi.org/10.1037/tra0000840

[19] Francois, B., Leiger, D., Cortaredona, S., Verger, P. and Peretti-Watel, P. (2020) Would We Recover Better Sleep at the End of Covid-19? A Relative Improvement Observed at the Population Level with the End of the Lockdown in France. Sleep Medicine, 78, 115-119. https://doi.org/10.1016/j.sleep.2020.11.029

[20] Salzman, L.Y., Hansel, T.C. and Bordnick, P.S. (2020) Loneliness, Isolates, and Social Support Factors in Post-COVID-19 Mental Health. Psychological Trauma: Theory, Research, Practice and Policy, 12, S55-S57. https://doi.org/10.1037/tra0000703

[21] Torres-Pagán, L. and Terepka, A. (2020) School-Based Health Centers during Academic Disruption: Challenges and Opportunity in Urban Mental Health. Psychological Trauma: Theory, Research, Practice and Policy, 12, S276-S278. https://doi.org/10.1037/tra0000611

[22] Rettie, H. and Daniels, J. (2020) Coping and Tolerance of Uncertainty: Predictors and Mediators of Mental Health during the COVID-19 Pandemic. American Psychologist. (Advance Online Publication) https://doi.org/10.1037/amp0000710

[23] Lisita, E., Benjamin, K.S., Chun, S.K., Skalisky, J., Hammond, L.E. and Mezulis, A.H. (2020) Loneliness among Young Adults during Covid-19 Pandemic: The Mediational Roles of Social Media Use and Social Support Seeking. Journal of Social and Clinical Psychology, 39, 708-726. https://doi.org/10.1521/jscp.2020.39.8.708

[24] Papaconstantinou, E. Shearer, H., Fynn-Sackey, N., Smith, D., Taylor-Vaisey, A. and Cote, P. (2019) The Association between Chronotype and Mental Health Problems in a University Population: A Systematic Review of the Literature. International Journal of Mental Health and Addiction, 17, 716-730.

https://doi.org/10.1007/s11469-018-0006-6

[25] Brooks, S.K., Webster, R.K., Smith, L.E., Woodland, L., Wessely, S., Greenberg, N. and Rubin, G.J. (2020) The Psychological Impact of Quarantine and How to Reduce it: Rapid Review of the Evidence. The Lancet, 395, 912-920.

https://doi.org/10.1016/S0140-6736(20)30460-8

[26] Brooks, P.R., Girgenti, A.A. and Mills, M.J. (2009) Sleep Patterns and Symptoms of Depression in College Students. College Student Journal, 43, 464-472.

[27] Zhou, S.-J., Wang, L.-L., Yang, R., Yang, X.-J., Zhang, L.-G., et al. (2020) Sleep Problems among Chinese Adolescents and Young Adults during the Coronavirus-2019 Pandemic. Sleep Medicine, 74, 39-47.

https://doi.org/10.1016/j.sleep.2020.06.001

[28] Mah, C.D., Kejirian, E.J., Marcello, B.M. and Dement, W.C. (2018) Sleep Quality and Insufficient of a Collegiate Student-Athlete Population. Sleep Health, 4, 251-257. https://doi.org/10.1016/j.sleh.2018.02.005

[29] Sexton-Radek, K. (2014) A Look at Worldwide Sleep Disorders. Journal of Sleep Disorders Therapy, 2, Article No. 115. https://doi.org/10.4172/2167-0277.1000115 
[30] Sexton-Radek, K. (2020) College Student Sleep Quality Following Sleep Class. Health, 12, 1409-1414. https://doi.org/10.4236/health.2020.1210102

[31] Sexton-Radek, K., Baxter, E., Burkes, B., Dinardi, A. and Levitt, T. (2020) Sleep Health: A Prominent Public Health Concern in the Time of COVID-19 Pandemic. American Journal of Medicine and Public Health, 1, Article No. 1008.

[32] Sexton-Radek, K., Burkes, B., Levitt, T., Baxter, E. and Dinardi, A. (2020) Global Sleep Health in a COVID-19 Virus Infected World. International Medicine, 2, 99-101. https://doi.org/10.5455/im.102662

[33] Sexton-Radek, K. and Rubenfeld, A. (2017) Perspectives on World Sleep Disturbances. In: Stout, C., Ed., Why Global Health Matters Has to Actually Make the World a Better Place, Medical Health Care Delivery, Kentucky, 131-140.

[34] Kumar, A.K. and Sherkhane, M.S. (2018) Assessment of Gadgets Addiction and Its Impact on Health among Undergraduates. International Journal of Community Medicine and Public Health, 5, 3624-3628. https://doi.org/10.18203/2394-6040.ijcmph20183109

[35] Hysig, M., Pallesen, S., Stormack, K.M., Lundervold, A.J. and Sivertsen, B. (2013) Sleep Patterns and Insomnia among Adolescents: A Population-Based Study. Journal of Sleep Research, 22, 549-556. https://doi.org/10.1111/jsr.12055

[36] Gowen, L.K. (2013) Online Mental Health Information Seeking in Young Adults with Mental Health Challenges. Journal of Technology in Human Service, 31, 97-111. https://doi.org/10.1080/15228835.2013.765533

[37] Harvey, A.G. (2009) A Transdiagnostic Approach to Treating Sleep Disturbance in Psychiatric Disorders. Cognitive Behavioral Therapy, 38, 35-42. https://doi.org/10.1080/16506070903033825

[38] Henderson, J. (2010) Students Spend More Time with Digital Gadgets than in Class. https://www.stltoday.com/entertainment/books-and-literature/book-blog/studentsspend-more-time-with-digital-gadgets-than-in-class/article cfa3d57a-a515-579f-87 ab-af4b91fb6a75.html

[39] Walch, O.J., Cockran, A. and Forger, D.B. (2016) A Global Quantification of "Normal" Sleep Schedule Using Smartphone Data. Science Advances, 2, Article ID: e1501705. https://doi.org/10.1126/sciadv.1501705 